\title{
Perubahan Kreativitas Seni Sebuah Proses Simbolis Dalam Kategori Sejarah
}

\author{
I Gusti Ngurah Seramasara \\ Fakultas Seni Pertunjukan, Institut Seni Indonesia Denpasar \\ E-mail penulis : aseramasara@gmail.com
}

Perubahan kreativitas seni tidak bisa dipisahkan dengan perubahan struktur masyarakat Bali. Perubahan struktur masyarakat Bali merupakan dinamika pergerakan masyarakat dari struktur tradisional menuju pada struktur modern. Struktur masyarakat modern di Bali muncul sebagai dampak dari berkembangnya kekuasan kolonial Belanda, yang berimplikasi terhadap perubahan kreativitas seni dari yang bersifat pengabdian menuju pada kreativitas komersiil. Perubahan biasanya dilihat sebagai sebuah evolusi dari periode ke periode, dan setiap realitas dalam satu periode digeneralisasikan mewakili mewakili jaman, padahal setiap jaman terdapat tingkat perubahan yang berbeda. Tulisan ini ingin melihat perbedaan perubahan dalam satu jaman melalui konsep transformasi struktural dalam kategori sejarah.

Untuk menjelaskan perubahan kreativitas seni sebuah proses simbolis dalam kategori sejarah, digunakan metode penelitian sejarah, dengan cara mengumpulkan sumber (heristik), kemudian melakukan kritik sumber, untuk mengetahui sumber yang sesuai dengan penulisan, kemudian melakukan interpretasi yang akhirnya dilanjutkan dengan sintesis yaitu menulis hasil penelitian

Transformasi struktural dalam masyarakat Bali terutama di Ubud, antara kategori tradisional dengan kategori modern mengalami integrasi kultural, karena prinsip-prinsip pengabdian sebagai norma dan budaya tradisional, dapat hidup terintegrasi dengan prinsip-prinsip komersiil, sesuai dengan perkembangan jaman. Kreativitas seni sebagai proses simbolis dalam memaknai realitas dapat dipisahkan antara kepentingan untuk pengabdian dengan kepentingan untuk komersiil yang didukung oleh perkembangan Pariwisata yang menempatkan Ubud khususnya dan Bali pada umumnya sebagai Pasar Internasional.

Kata kunci :Katagori sejarah, Proses Simbolis, Perubahan Kreativitas.

\section{Change In Art Creativity Of A Simbolic Process In Category Of History}

Changes in artistic creativity can not be separated by changes in the structure of Balinese society. The changing structure of Balinese society is the dynamics of the movement of society from the traditional structure to the modern structure. The structure of modern society in Bali emerged as the impact of the development of Dutch colonial power, which had implications for the changing of artistic creativity from the devotion to commercial creativity. Change is usually seen as an evolution from period to period, and every reality in one period is generalized representing the era, yet every time there is a different rate of change. This paper seeks to see the difference of change in one age through the concept of structural transformation in the category of history.

To explain the change of art creativity of a symbolic process in the category of history, historical research methods is used, by collecting the source (heuristic), then doing source criticism to find out the appropriate source of the writing, then do the interpretation which was ultimately followed by the synthesis of writing research results.

The structural transformation of Balinese society especially in Ubud, between traditional categories and modern ones, has cultural integration because the principles of devotion as a norm and traditional culture can live in an integrated fashion with commercial principles, in keeping with the times. Artistic creativity as a symbolic process in interpreting reality can be separated between the interests of dedication with the interests for commercial supported by the development of Tourism which puts Ubud in particular and Bali in general as International Market.

Keywords: Historical category, Symbolic process, and Creativity Change 


\section{PENDAHULUAN}

Seni sebagai hasil kreativitas manusia merupakan proses simbolis untuk memaknai realitas. Dalam memaknai realitas,kreativitas senisangat ditentukan oleh perubahan sosial dalam masyarakat. Perubahahan sosial dalam masyarakat Bali merupakantransformasi struktural, dari katagori tradisional menuju pada katagori modern. Masyarakat dalam katagori modern dipahami ketika masuknya pengaruh Belanda, sehingga modernisasisering disejajarkan dengan westernisasioleh bangsa Indonesia. Pengaruh Belanda secara resmi masuk di Bali,sejak jatuhnya Kerajaan Badung tahun 1906 dan sejak Jatunya Kerajaan Klungkung tahun 1908, yang didorong oleh kepentingan ekonomi (Seramasara, 1997:1-3). Dengan dikuasainya Bali oleh pemerintah kolonila Belanda telah berimplikasi pada perubahan kreativitas seni, dari yang bersifat pengabdian menuju pada seni yang bersifat komersil.

Kreativitas merupakan kemunculan ide baru secara terus menerus, sebagai hasil interaksi antara manusia dengan manusia dan manusia dengan lingkungan (Lauer, 1989: 193-194). Berdasarkan pandangan itu maka perubahan kreativitas seni merupakan hasil interaksi antara seniman Barat dengan seniman Bali,Perubahan kreativitas merupakan kegiatan manusia dalam menciptakan makna terhadap realitas, bisa dalam bentuk agama, filsafat, ilmu pengatahuan, mitos, bahasa maupun seni (Cassirer, 1956). Perubahan kreativitas seni tidak bisa dipisahkan dengan terjadinya transformasi struktural dalam masyarakat Bali. Bagaimana perubahan kreativitas seni sebagai proses simbolis dalam masyarakat Bali ?, kemana arah perubahan itu ?, merupakan pokok kajian dalam tulisan ini. Konsep transformasi strukturaldalam memahami masyarakat Bali, sudah sangat konprehensif dan secara periodik telah dibahas dan dikaji oleh Jean Couteaudan Wiryatnaya, ed, (1995).Berdasarkan pada konsep transformasi struktural dalam katagori sejarah, maka tulisan ini bertujuan untuk mendiskusikan perubahan kreativitas seni sebagai proses simbolisdalam memaknai realitas masyarakat Bali saat ini.

\section{KERANGKA KONSEPTUAL PERUBAHAN KREATIVITAS SENI.}

Perubahan merupakan dinamika pergerakan masyarakat Bali dari masa lampau kemasa yang akan datang, dari yang sederhana menuju pada masyarakat yang lebih maju, dari yang tradisional menuju yang modern. Perubahan merupakan gejala sosial yang melekat (inheren) dalam setiap perkembangan. Perubahan adalah peningkatan kapasitas untuk mempertahankan eksistensi, adaptasiterhadap lingkungan serta, efektivitas untuk mencapai tujuan (Sartono, 1992: 162). Perubahan merupakan pergerakan masyarakat yang didorong oleh berbagai faktor di antaranya adalah faktor politik danfaktor ekonomi.

Transformasi struktural adalah sebuah konsep yang melihat adanya perubahanstruktursosial dan hubungan sosial (Jean Couteau, 1995). Perubahan dalam masyarakat ditandai oleh: 1) munculnya sistem produksi baru, komersialisasi, komunikasi, dan moderniasi teknologi, 2) munculnya elit baru, dengan struktur kekuasaan baru dan sistem politik yang baru (Sartono, 1992: 100). Konsep transformasi strukturaldapat digunakan untuk memahami perubahan kreativitas seniman dalam katagori tradisional menuju pada katagori modern. Kreativitas seni dalam katagori modern sangat dipengaruhi oleh kepentingan kapitalisme dan tehnokapitalismesehingga, proses simbolis dalam katagori sejarah yang ditawarkan oleh Kuntiwijoyo (1999: 6), dapat digunakan sebagai krangka konseptual untuk menjelaskan perubahan kreativitas seni di Bali.

Krangka konseptual proses simbolis yang ditawarkan oleh Kuntowijoyo (1999:6), dapat dipahami melalui skema berikut ini. 


\begin{tabular}{|l|l|l|l|}
\hline \multirow{2}{*}{$\begin{array}{c}\text { KATEGORI } \\
\text { SEJARAH }\end{array}$} & \multicolumn{3}{|c|}{ PROSES SIMBOLIS } \\
\cline { 2 - 4 } & Lembaga & Simbol & Norma \\
\hline $\begin{array}{l}\text { Tradisional } \\
\text { Patrimonial }\end{array}$ & $\begin{array}{l}\text { Masyarakat Abdi Dalem } \\
\text { Raja, Perintah }\end{array}$ & $\begin{array}{l}\text { Mistis } \\
\text { Mistis }\end{array}$ & $\begin{array}{l}\text { Komunal } \\
\text { Kepatuhan }\end{array}$ \\
\hline Kapitalis & $\begin{array}{l}\text { Profesional,Pasar, } \\
\text { Penawaran }\end{array}$ & Realis & Individualistis \\
\hline Tehnokapitalis & $\begin{array}{l}\text { Profesional, Negara, } \\
\text { Pesanan }\end{array}$ & $\begin{array}{l}\text { Pseudo } \\
\text { Realis }\end{array}$ & $\begin{array}{l}\text { Modifikasi } \\
\text { Prilaku }\end{array}$ \\
\hline
\end{tabular}

\section{PROSES SIMBOLIS PERUBAHAN KREATIVITAS DALAM KATAGORI SEJARAH}

Proses simbolis merupakan perubahan kreativitas seni dalam memaknai realitas, dapat menyebabkan terjadinya disintegrasi kultural dan bisa juga terjadi integrasi kultural. Menurut Read (1970: 128), integrasi kultural tidak akan terjadi apabila metode produksi atau penciptaan karya seni tidak lagi berdasarkan pilihan yang bebas dari senimannya, tetapi berdasarkan keharusan ekonomi. Ketika keharusan ekonomi yang menuntut kreativitas seni maka, seniman dalam masyarakatkatagori tradisionalakan berada dalam kondisitransisi, antara menerima perubahan dan menolak perubahan.

Artinya, kondisi transisi itu disatu pihak seniman ingin tetap mempertahankan tradisi dan dipihak lain perubahan tidak dapat dihindari. Transisi itu dialami oleh masyarakat Bali ketika konsep Industri Pariwisata digulirkan oleh pemerintah RI berdasarkan Impres No 9 tahun 1969. Ada kekhawatiran bahwa, budaya Bali akan digilas oleh kepentingan kapitalis. Masyarakat Bali sangat menyadari adanya konsep Negara Mawe Tata, dan Desa Mawe Cara, bahwa kebijakan negara harus diikuti, tetapi tata cara lokal harus dipertahankan. Untuk mengaitkan kepentingan negara dengan kepentingan lokal, munculah pemikiran adaptif yang disebut konsep Pariwisata budaya dan klasifikasi seni menjadi Wali, Bebali dan Balih-Balihan.

Tulisan ini akan melihat perubahan kreativitas seni sebagai sebuah proses transisi, antara katagori tradisional dan katagori modern (kapitalis maupun tehnokapitalis).Transisi antara kepentingan negara dengan kepentingan lokal,transisi antara kepentingan sosial dan kepentingan ekonomi, yang telah menempatkan seni budaya Bali berada dipersimpangan jalan seperti yang dituliskan sebagai judul buku, Bali di Persimpangan Jalan Sebuah Bunga Rampai yang diedit oleh Jean Couteau dan Usadi Wiryatanaya (1995). Transisi perubahan kreativitas seni dapat dipahami melalui proses sejarah, sbb:

\subsection{Katagori Tradisional.}

Dalam katagori tradisional, kreativitas seni masyarakat Bali tunduk pada struktur masyarakat kerajaan. Struktur masyarakat kerajaan adalah,abdi dalem, yang dijiwai oleh prinsip-prinsip pengabdian. Prinsip pengabdian kreativitas seni diletakan pada kepentingan agama maupun terhadap kepetingan sosial. Kedudukan raja di Bali, disamping sebagai kepala pemerintahan juga sebagai pengayom agama, sehingga pengabdian rakyat kepada raja sebagai elit tradisional tidak hanya untuk kepentingan istana, juga untuk kepentingan agama.Dengan demikian kreativitas seniman dalam memaknai realitas sosial seperti itu, telah menciptakan karya seni sebagai simbol mistis yang dilembagakan sebagai sebuahkepatuhan pada raja dan agama. Karya seni yang diciptakan bersumber dari legenda, mitos dan ajaran agama dengan norma komunal atau kebersamaan.

Misalnya : 1) Tari Rejang, untuk kepentingan upacara merupakan salah satu bentuk pengabdian pada upacara agama di pura. Tari Rejang merupakan simbol mistis turunnya para bidadari dari kahyangan untuk menyaksikan upacara, dilakukan secara kolektif dengan norma kebersamaan (komunal). Menari rejang dalam kaitannya dengan upacara, tidak membutuhkan profesionalisme sebagai penari, setiap gadis yang ada di pura bisa ditunjuk untuk ikut menari rejang. 2) Tari Sanghyang, merupakan jenis tari kerauhan, yang dipercaya sebagai turun Hyang untuk menghalau berbagai wabah menyakit yang menimpa masyarakat. 
Penari Sanghyang tidak membutuhkan profesionalisme, penarinya ditunjuk oleh pimpinan upacara, anak gadis yang belum kotor kain. 3) Tari Sanghyang diiringi dengan gending-gending Sanghyang dan koor laki-laki yang dikuti oleh warga desa tanpa membutuhkan profesionalisme. Sama dengan tari Rejang normanya adalah kebersamaan. 4) Tari baris tombak, dan taribaris lainnya sebagai pengiring upacara merupakan pengabdian kepada upacara agama, yang diikuti oleh warga desa secara kolektif dan tidak memerlukan profesionalisme sebagai seniman. Siapa saja yang ditunjuk harus mau menari untuk kepetingan upacara.

Dalam seni rupa, proses simbolis dalam katagori tradisional juga terjadi pada saat membuat Bade dan Lembu untuk upacara pengabenan (pelebon), dilakukan secara bersama-sama dengan prinsip pengabdian, sehingga seniman tidak memperhitungkan upah. Dalam kegiatan pengabdian siapa yang datang ikut mengukir dan ikut merakit Bade atau Lembu. Kreativitas seni seperti itu merupakan merupakan kegiatan kreatif seniman untuk menciptakan simbol-simbol upacara pembakaran mayat, dengan norma kebersamaan (komunal).

Disamping kreativitas seni tersebut di atas muncul berbagai karya seni sebagai hasil kreativitas seniman seperti: Gambuh, Legong Kraton. Wayang Wong dan Parwa, sebagai salah satu bentuk pengabdian pada raja untuk memperkuat kekuasaan (kultus dewa raja). Pengabdian kepada upacara agama muncul, Tari Rejang, Baris Gede, Wayang Lemah, Wayang Sapuh Leger, Wayang Lemah, Wayang Sudamala, yang ditetapkan dalam Plutuk Bebatenan. Dalam bidang seni rupa seperti, seni lukis, seni ukir dan seni patung juga digunakan sebagai hiasan Pura dan Puri, dilembagakan sebagai sebuah pengabdian, memiliki simbol mistik dengan norma komunal. Karangan Boma sebagai simbol Kala Makara, penjaga pintu gerbang. Patung simbol mistik kekuatan dewa. Seni ukir seperti Bedawang Nala, merupakan simbol penyaangga bumi, dst.

Proses simbolis kreativitas seniman dalam masyarakat Bali merupakan perpaduan dua kekuatan sorga dan dunia, baik dan buruk yang sering dikenal dengan konsep rwa bineda. Dikotomi antara konsep mistik yang sakral di Bali dengan konsep realitas yang dianggap prafane telah banyak diulas oleh Eisemen(1994) dalam bukunya, Sekala Niskama, Essays on Religion, Ritual, and Art, Volume I.

\subsection{Katagori Kapitalis}

Perubahan struktur masyarakat Bali dari katagori tradisional kekatagori kapitalistelah menimbulkan pergeseran kreativitas seni dari yang bersifat pengabdian menuju pada kreativitas seni yang bersifat komersial. Pergeseran itu ditandai dengan berkembangnya kekuasaan kolonial pada awal abad ke 20, dengan jatuhnya kerajaan Badung tahun 1906 dan jatuhnya kerajaan Klungkung tahun 1908. Munculnya struktur kolonial dengan adanya jabatan kontrolir dalam sistem kerajaan, menunjukan adanya dualisme elit dalam sistem pemerintahan yaitu elit kolonial dan elit tradisional (raja dan pejabat kerajaan). Munculnya dualisme elit telah mendorong kreativitas seni menjadi ambivalensi, yaitu untuk kepentingan komersiil disatu pihak dan untuk kepentingan pengabdiandipihak lain, dalam rangka mempertahankan seni budaya sebagai warisan tradisional.

Usaha untuk mempertahankan seni budaya Bali, pada mulanya adalah untuk membendung usaha Pendeta Kristen di Belanda untuk mengembangkan Missie Zending. Usaha itu sudah pernah dilakukan pada pertengah abad ke-19, dengan mendatangkan pendeta-pendeta Kristen Protestan Belanda di Utrecht (de Utrechtse Zending Genootschap), tetapi gagal (Last, 1955: 115-123; Agung, 1993:

21-22). Anggapan bahwa Missie Zending akan berhasil, karena Bali telah berada di tangan kekuasaan kolonial Belanda, telah mendorong datangnya Missie Zending pada tahun 1920. Pemerintah Belanda menganggap Hindia Belanda adalah bagian dari wilayah Kerajaan Belanda, sehingga disebut dengan "Nederlands Indie". Menurut Soedarsono (2003: 13), kata "Nederlands Indie" artinya adalah India miliki Belanda. Yang dimaksud dengan India itu adalah Indonesia, karena pada waktu itu belum ada kata Indonesia yang ada adalah Nusantara. Bali sebagai bagian dari Nusantara, sudah jelas merupakan bagian dari wilayah kerajaan Belanda.

Kedatangan Missie Zending ke Bali pada tahun 1920, bukan dengan cara mendatangkan Pendeta, tetapi dengan mendirikan sekolah berbahasa Belanda yaitu Hollands Inlandsche School (HIS). Melalui sekolah itu siswa dipengaruhi dengan 
ajaran agama Kristen kemudian dibaptis menjadi penganut Kristen (Agung, 1989: 21). Cara itupun gagal karena, Tjokorde Raka Soekawati sebagai anggota Volksraad di Batavia, dari Puri Ubud menetang keras usaha Missie Zending, yang kemudian diikuti oleh raja-raja Bali, serta tokoh-toko penganut agama Hindu di Bali.

Perlawanan terhadap Missie Zending itu merupakan embrio berdirinya Yayasan Siladarma di Klungkung pada tahun 1930 an, dengan mendirikan sekolah yang disebut dengan Neutral Hollands Indische School (NHIS), Sekolah itu mengembangkan pendidikan tentang seni budaya Bali untuk mebendung Missie Zending. Pada tahun 1939, usaha-usaha itu mencapai puncaknya yang disebut dengan Balisering atau membelikan Bali. Artinya agama Hindu, adat istiadat serta, berbagai jenis kesenian yang memperkuat agama dan adat harus tetap dipertahankan.

Sejalan dengan usaha untuk membendung Missie Zending, maka kesenian sebagai penyangga budaya Bali harus di perkuat, sehingga muncul yayasan seni pertama di Bali yang disebut dengan Pita Maha, pada tahun 1936, yang dimotori oleh Tjokode Agung Soekawati bersama dengan, R. Bonet, Walter Spies, I Gst Nyn Lempad, dan Seniman Lukis Lainnya di Ubud. Yayasan Pita Maha itulah yang kemudian bergerak, mempromosikan seni lukis Bali, dan memperbaharui cara berpikir dan kreativitas seniman Bali. Peranan Tjokorde Agung Soekawati, Bonet dan Walter Spies, sangat sentral dalam memberikan arah perkembangan kreativitas seniman Bali. Pertemuan Seniman Lukis Bali dibawah kendali Tjokorde Agung Soekawati dan R Bonet, merupakan pertemuam antara tradisidan modern. Prinsip-prinsip kreativitas tradisional adalah pengabdian, sedang prinsip modern adalah seniman harus hidup dengan karya seninya. Seni harus dapat menembus pasar internasional. Dengan demikian seni tradisional dipromosikan keluar negeri, kemudian kreativitas seni di arahkan agar memiliki identitas modern.Pertemuan antara tradisi dan modernisme kesenian Bali, sampai saat ini masih dapat disaksikan di Ubud, sebagai pasar internasional seni budaya Bali, karena Ubud telah menjadi daerah wisata.
Perkembangan Ubud sebagai daerah wisata tidak lepas dari proses sejarah dalam mempertahankan seni budaya dan agama Hindu di Bali yang telah dirintis oleh Resident Liffrinck, dengan mengarahkan para peneliti untuk meneliti agama, kesenian dan budaya Bali, serta mendirikan Gedung Kirtya tahun 1928. Didirikannya Gedung Kirtya bertujuan untuk menyimpan hasil-hasil penelitian, lontar dan arsip kolonial Belanda yang semula bernama, Liffrinck Kirtya van der Tuuk. Para peneliti dan seniman yang mengahsilkan penelitian seni dan budaya Bali antara lain :

1)Walter Spies dan R Goris, melakukan penelitain yang dituliskan dalam bukunya yang berjudul "Overzicht van Dans en Tooneel in Bali", dalam Majalah Djawa, No 6-5 (Tjdschrift van het Java Institut, 1937), menyebutkan berbagai jenis yang ada di Bali baik yang berfungsi Sakral maupun Sekuler.

2) Berbagai jenis seni pertunjukan Sakral maupun Sekuler termasuk dramatari juga di tulis oleh Baryl de Zoete dan Walter Spies, dalam bukunya yang berjudul, Dance and Drama in Bali. Kuala Lumpur: Oxford University Press, 1973.

3) J. Kat, " Barong op Bali” dalam Madjalah Djawa, tahun ke IV (Tijdschrift van het Java Institut, 1924), seni pertunjukan barong berfungsi keagamaan dan ada juga yang berfungsi profane.

4) Tjokorde Raka Soekawati, " De Sahnyang op Bali, dalam Madjalah Djawa tahun ke V. ( Tijdschrift van het Java-Institut, 1925), menjelaskan fungsi tari Sanghyang adalah untuk menghalau berbagai wabah penyakit yang mengganggu masyarakat pada sasih ke 6 dan ke 9. Sangat dapat disadari bahwa tanpa hasil penelitian para peneliti di atas, kita akan kehilangan sumber-sumber sejarah (babad) dan, kekayaan seni budaya.

Sejalan dengan usaha pelestarian budaya, pemerintahan Residen Liffrinck van der Tuuk, pemerintah kolonial Belanda mendorong perkembangan pariwisata di Indonesia dengan keputusan Gubernur Jendral tahun 1910-1912, atas terbentuknya Vereeneging Toeristen Verkeer (VTV). Perusahan itu merupakanbadan official tourist bureau (trevel biro) pada waktu itu (Yoeti, 1985:24). Kemudian didirikan Agen Perjalanan (Travel Agent) di Jakarta tahun 1926, yang disebut dengan Lissone Lindoman (LISLIND). Tahun 1928 LISLIND, dilebur menjadi NITOUR (Nederlandsche Indische Touristen 
Bureau) yang merupakan anak usaha Koninklij Paketvaarkt Maskappij (KPM) dan Koninklij Lukcpaarkt Maskappij (KLM). Untuk kepentingan akomudasi (penginapan didirikan Bali Hotel dan Kuta Beach Hotel (Yoeti, 1985: 25).

Usaha pelestarian seni budaya itu ternyata menjadi daya tarik wisata, sehingga Bali sebagai daerah kunjungan wisata yang dicari adalah tradisi dan seni budaya. Informasi dari hasil penelitian yang dilakukan tentang Bali, menunjukan bahwa kesenian Bali adalah seni ritual yang diciptakan sebagai salah satu bentuk pengabdian. Untuk mempertahankan budaya Hindu di Bali maka berbagai jenis kesenian itu harus tetap dipertahankan sebagai bagian dari upacara. Penelitian itu memberikan informasi bahwa kesenian Bali merupakan sebuah integrasi kultural antara seni dan agama yang tak dapat dipisahkan dalam masyarakat Bali. Pentingnya memepertahankan seni budaya Bali yang berimplikasi terhadap kehidupan masyarakat telah dilaporakan oleh J J Caron dalam, Memorie van Overgave der Resident van Bali en Lombok, 1929 yang menyatakan bahwa adat dan agama Hindu di Bali telah menimbulkan Jiwa Seni.

Oleh karena itu musik, arsitektur, tari dan berbagai jenis kesenian perlu dipertahankan. Ternyata hasil penelitian itu medorong daya tarik wisatawan datang ke Bali untuk menikmati seni dan budaya Bali, sehingga penelitian itu dapat memperkuat kebijakan pemerintah Belanda untuk mengembangkan Bali sebagai daerah pariwisata. Berkembangnya pariwisata sejak awal abad ke 20, telah menimbulkan kreativitas seni sebagai proses simbolis yang mengarah pada kepentingan ekonomi kolonial. Pariwisata telah menimbulkan terjadi difrensiasi fungsional kesenian Bali antara kreativitas seni untuk pengabdian dan seni sebagai produksi ekonomi untuk kepentingan pariwisata.

Misalnya: Tari Legong yang dipentaskan untuk kepentingan pariwisata, di Bali Hotel, belum ada kemasan seni, dipentaskan mengikuti pola-pola yang ada secara nyata (riil) seperti apa adanya. Muncul gaya pelegongan seperti gaya Peliatan, gaya Saba, sebagai produksi baru dalam bentuk profesionalisme. Muncul berbagai cipataan baru, hasil kreativitas seniman yang bersifat konsumtif untuk dipasarkan, seperti, Trunajaya, Panji Semirang, Wiranata, Tari Kebyar. Muncul difrensiasi fungsi, disatu pihak seni tetap digunakan sebagai pengabdian pada masyarakat untuk kepentingan agama maupun kepentingan sosial lainnya dan dipihak lain untuk kepentingan pariwisata. Kreativitas itu muncul karena terjadinya transformasi struktural yang mengarah pada katagori kapitalisme. Dalam bidang seni rupa, muncul seniman lukis, patung, ukir secara professional, yang mendorong karyanya secara realistis sebagai hasil karya seniman apapun alirannya, naturalisme, ekspresionisme, impresionisme, suryalisme, maupun tradisi, tetap saja merupakan karya individual secara profesionalisme.

\section{Katagori Tehno Kapitalis (Tehnokrasi).}

Perkembangan tehnologi tak dapat dipisahkan dengan sistem kapitalisme yang memanfaatkan kreativitas seni sebagai mesin sosial. Artinya seni merupakan penggerak kehidupan manusia, sehingga profesionalisme sangat tergantung pada kepentingan negara. Ketika negara memajukan Bali sebagai daerah pariwisata, maka seniman harus mampu berkreativitas untuk memenuhi kepentingan pariwisata sebagai kebijakan negara. Menurut Kuntowijoyo, kebijakan negera sering merupakan penolakan terhadap realisme dan muncul pesuedo realisme, sehingga kesenian tidak lagi diciptakan tetapi diproduksi untuk mendukung kebijakan negara. Inpres No 9 tahun 1969, yang mengisyaratkan Bali untuk menjadi daerah wisata dengan mengembangkan Bali sebagai Industri Pariwisata, menunjukan adanya penolakan terhadap budaya Bali yang bersifat ritual agar budaya Bali bersifat komesrsiil.

Gejala komersiil mulai mencapai bentuknya pada tahun 1974, ketika kunjungan wisata meningkat cukup besar, sebagai dampak konfrensi PATA (Pasific Asia Tourism Asosiation). Kreativitas seni mengarah pada sistem produksi untuk memenuhi kebutuhan wisata. Menurt Read, kreativitas seniman dalam hal ini tidak lagi ditentukan oleh pengalaman estetik dan rasa seni (sense of art) dari senimannya, tetapi ditentukan oleh kebutuhan pasar (Read, 1970: 128). Dengan demikian kreativitas seni tidak lagi ditentukan oleh pilihan yang bebas dari senimanya tetapi berdasarkan tuntutan konsumen dan keharusan ekonomi.

Misalnya: muncul seni kemasan yang merupakan hasil peniruan dari aslinya, seperti, Legong Kraton, 
Barong dikemas menjadi seni dengan durasi yang diperpendek (tidak realis lagi atau sesuai dengan aslinya), tetapi sesuai dengan waktu dan kemampuan bayar wisatawan. Seni sakral di tirukan, dengan kemasan yang disesuaikan dengan kebutuhan wisatawan, seperti koor laki-laki tari Sanghyang dijadikan tari Kecak dan tari Sanghyang atau Sanghyang Jaran disebut dengan tari api (fire dance), yang sangat diminati oleh wisatawan. Seniman yang mengkemas koor laki-laki tari Sanghyang menjadi Kecak, karena sangat dibutuhkan oleh wisatawan adalah Walter Spies dan Baryl de Zoete bersama dengan seniman Bedulu pada tahun 1935, kemudian tahun 1937 muncul Kecak di desa Bona, dan tahun 1938 muncul Kecak di desa Kemenuh (Bandem, 1983: 42). Tari Barong sebagai seni sakral di sekulerkan untuk kepetingan wisatawan dengan membuat Barong tiruan, dan prosesi sakral tiruan. Kondisi seperti itu menurut Soedarsono disebutkan sebagai psuedo tradisional art (Soedarsono, 1999: 3), dan menurut Konrowijoyo disebut psuedo realiatas serta munculnya modifikasi prilaku (Kuntowijoyo, 1999: 6).

Modifikasi prilaku maksudnya adalah prilaku berpura-pura, karya tiruan atau palsu dikatakan dengan berbagai cara meyakinkan konsumen. Dalam katagori tehnokapitalis, bentuk-bentuk tehnologi dan informasi baru menjadi pusat perubahan, sehingga dari tatanan sosial yang produktif (produk original realitis dan tidak terjadi pengulangan), menjadi tatanan sosial yang reproduktif (peniruan dan pengulangan berkali-kali karena pesanan). Kondisi itu terjadi, karena adanya kepentingan negara, berkuasanya tehnologi dan modal (kapital). Dalam kondisi seperti itu Baudrillard, menyebutkan kepribdaian berpura-pura adalah simulacra, artinya, konsumen dalam mengkonsumsi hasil produksi bukan berdasarkan kebutuhan tetapi berdasarkan pencitraan (Haryanto, 2012: 298).

\section{PERUBAHAN KREATIVITAS SENI SAAT INI DI BALI.}

Kreativitas seni dalam masyarakat Bali, sangat dipengaruhi oleh kepentingan untuk mempertahankan desa adat, dengan konsep desa kala patra, atau konsep desa mawe cara. Konsep desa kala patra atau desa mawe cara, menunjukan adanya perbedaan tata cara pengaturan adat dan sistem upacara yang harus tetap dipertahankan oleh negara sebagai pemegang kebijakan tertinggi yang disebut dengan negara mawe tata. Antaran desa dan negara terjadi adaptasi kultural untuk mendukung kebijakan negara dalam pengembangan pariwisata. Struktur masyarakat desa mengalami perubahan yang semula tidak mengerti pariwisata menjadi mengerti pariwisata, sehingga struktur masyarakat desa diarahkan untuk mendukung pariwisata. Dengan demikian kreativitas seni mengalami difrensiasi fungsional (Sartono, 1992:100), artinya kreativitas seni untuk pengabdian masyarakat tetap dipertahankan, karena menjadi daya tarik wisata, kemudian kretivitas seni sebagai kegiatan professional muncul berserakan sebagai konsumsi wisata yang dapat dibayar dengan uang.

Perkembangan pariwisata yang mendorong munculnya kreativitas professional untuk konsumsi pariwisata, dapat digolongkan sebagai kreativitas seni dalam katagori kapitalis. Artinya seniman berkreativitas bukan dituntut untuk kepentingan pengabdian saja tetapi untuk kepentingan pasar. Pariwisata di Bali telah memunculkan pasar baru bagi hasil kreativitas seniman yang professional yaitu pariwisata. Akan dapat dibayangkan bahwa tanpa perkembangan pariwisata, kreativitas seni di Bali tidak bisa bertahan hanya untuk pengabdian pada masyarakat. Perkembangan kreativitas itu bukan tanpa resiko, Menurut Read (1970:128), resikonya adalah kretivitas seni yang telah memasuki pasar, bukan lagi mementingkan realitas yang original, yang dapat memberikan kebebasan pada seniman untuk menuangkan pengalaman estetik dan rasa seninya (sense of art), tetapi untuk memenuhi tuntutan pasar. Untuk memenuhi tuntutan pasar akan terjadi produksi masal yang dapat dikerjakan dengan menggunakan tehnologi dengan melakukan reproduksi. Perkembangan kreativitas seni yang mengarah pada produksi masal untuk memenuhi tuntutan pasar, dapat dimasukan dalam katagori teknokapitalis.

Seniman professional tidak lagi berkreativitas untuk menciptakan karya seni tetapi cukup memberikan pengakuan (lisensi), yang dapat disebut dengan modifikasi prilaku. Dengan demikian makahasil kreativitas seni akan menjdi pseudo realitas, atau peniruan-peniruan terhadap yang sudah ada. Uraian di atas merupakan gambaran kreativitas seni yang ada saat ini di Bali sebagai dampak perkembangan pariwisata. Seting sosial masyarakat Bali saat ini menunjukan bahwa kreativitas seni dalam katagori 
tradisonal, katagori kapitalis serta katagori tehnokapitalis berbaur menjadi satu, merupakan bagian dari perkembangan struktur masyarakat Bali sebagai daerah wisata.

\section{SIMPULAN}

Perubahan kreativitas seniman sebagaiproses simbolis dalam memaknai perkembangan pariwisata di Bali, sangat ditentukan oleh terjadinya transformasi struktural berdasarkan katagori sejarah. Kreartivitas seni sebagai proses simbolis yang dilakukan oleh seniman Bali ditentukan oleh transformasi struktural dari jaman kerajaan ke jaman modern. Jaman kerajaan berjalan sebelum kedatangan kolonialisme Belanda dan tetap dipertahankan oleh kolonialisme Belanda dengan sistem pemerintahan Zelfbestuurder, tetapi rakyat tetap menegnalnya sebagai kerajaan karena raja sendiri yang disebut Zelfbestuur.

Sebelum kedatangan Belanda di Bali,proses simbolis kreativitas seni didasarkan atas pengabdianpada raja dan agama, kemudian setelah kedatangan kolonialisme Belanda,kreativitas seni sebagai proses simbolis mengalamidifrensiasi fungsional, disatu pihak untuk pengabdian pada agama dan dipihak lain untuk kepentingan komersiil. Difrensiasi dalam memaknai realitas di Bali, didominasi oleh perkembangan pariwsata, sehingga pariwisata ditempatkan dalam struktur sosial masyarakat Bali.

Penempatkan pariwisata dalam struktur sosial telah melahirkan bentuk adaptasi kreativitassebagai bagian dari strktur sosial, yang mampu mewujudkan integrasi kultural kreativitas seni antara katagori tradisional, katagori kapitalis, dan katagori tehnokapitalis. Kondisi seperti ini dalam kreativitas seni, terutama dalam seni lukis digerakan oleh munculnya Pita Maha, karena Pita Mahamampu mengintrasikan norma-norma tradisi dan modern, sehingga kreatvitas seni terintegrasi antara kepentingan pengabdian dengan kepentingan pasar.

\section{DAFTAR RUJUKAN}

Agung, Ide Anak Agung Gde, Kenangan Masa lampau Jaman Kolonial Hindia Belanda dan Jaman kedudukan Jepang di Bali. Jakarta: Yayasan Obor Indonesia, 1993.

Bandem, I Made, Ensiklopedi Tari Bali. Denpasar: Akademi Seni Tari Indonesia, 1983.
Caron, JJ. Memorie van Overgave der Resident van Bali en Lombok, 1929

Eliade, Mircea, The Sacred And Profane The Nature of Religion, The Significance of Religious Mith, Symbolism, and Ritual Within Life and Culture. New York: Harvers and Row Publishers, 1959.

Esemen, Fred B, Jr, Bali Sekala \& Niskala, Volume I, Essys on Religion, Ritual, and Art. Singapore: Periplus Editions, 1994.

Haryanto, Sindung, Spektrum Teori Sosial dari Klasik Hingga Postmodern. Yogyakarta: A-Ruzz Media, 2012.

Jean Couteau, "Transformasi Struktural Masyarakat Bali", dalam Usadi Wiryatnaya dan Jean Couteau (ed), Bali di Persimpangan Jalan 2 (Sebuah Bunga Rampai). Denpasar: Nusa Dua Indo Budaya, 1995.

Kartodierdjo, Sartono, Pendekatan Ilmu Sosial dalam Metodologi Sejarah. Jakarta: Gramedia Pustaka, 1992.

Kat, J, "De Barong op Bali”, dalam Madjalah Jawa tahun IV. Tijdschrift van het Java Instituut, 1924.

Last, Jeft, Bali: In de Kentring. Ansterdam: de Bezige Bij, 1955.

Lauer, Robert H, Perspektif Tentang Perubahan Sosial (terjemahan). Jakarta: Bina Aksara, 1989.

Seramasara, I Gusti Ngurah, "Sekularisasi Seni Pertunjukan di Bali Pada Tahun 1920-1974 (Tesis S-2). Yogyakarta: Program Pasca Sarjana Universitas Gadjah Mada, 1977.

Soekawati, Tjokorde Raka, "De Sanghyang op Bali, dalam Madjalah Jawa tahun V. Tijdschrift van het Java Instituut, 1925.

Soedarsono, RM, Seni Pertunjukan Indonesia \& Pariwisata. Bandung : Masyarakat Seni Pertunjukan Indonesia, 1999.

Soedarsono, RM, Seni Pertunjukan dari Perspektif Politik, Sosial, dan Ekonomi. Yogyakarta: Gadjah Mada University Press, 2003.

Spies, Walter en R.Goris, "Overzicht van Dans en Tooneel in Bali", dalam Madjalah Jawa, No 6. Tijschrift van het Java Instituut, 1937.

Yoeti, Oka A, Pengantar Ilmu Pariwisata. Bandung: Angkasa, 1985.

Zoete, Baryl de, Walter Spies, Dance and Drama in Bali. Kula Lumpur: Oxford University Press, 1973. 